\section{MATEMÁTICA E MÚSICA SOB UMA PERSPECTIVA HISTÓRICO/ EPISTEMOLÓGICA: MUDANÇAS CONCEITUAIS}

Oscar João Abdounur*

RESUMO: A passagem do final do século XV para o início do século XVI testemunhou o aparecimento da geometria como instrumento para resolução de problemas em música teórica e de forma não independente, mudanças na concepção de razão/número subjacente à música teórica. Neste período, o teórico musical e matemático Erasmus Horicius surgiu como um importante humanista alemão deste período envolvido com questóes musicais. Ele resgatou fontes gregas, possibilitando a teóricos da época o acesso a importantes frutos do reavivamento do interesse por textos antigos, sendo o primeiro, por exemplo, no Renascimento a aplicar explicitamente geometria euclidiana para resolver problemas em música teórica. Dentre os problemas considerados, Erasmus propôs uma divisão igual numérica do intervalo de tom inteiro, que pressupóe importantes transformações nas concepções de razão, em particular, na direção de promover a emergência da ideia de número real em contextos teório-musicais.

PALAVRAS-CHAVE: matemática/música, Renascimento, conceito de número, transformações estruturais.

ABSTRACT: The passage from the late fifteenth century to the early sixteenth century witnessed the emergence of geometry as a tool for solving problems in theoretical music and, not independently, changes in the conception of ratios/ number underlying theoretical music. In this passage, the musical theorist and mathematician Erasmus Horicius emerged as an important German humanist of this period involved with musical issues. He rescued Greek sources, enabling theorists of his time accessing important fruits of the revival of interest in ancient texts. He was the first, for example, in the Renaissance explicitly to apply Euclidean geometry to solve *abdounur@ime.usp.br

Instituto de Matemática, Universidade de São Paulo, Brasil 
problems in theoretical music. Among the problems considered, Erasmus proposed a numerical equal division of the whole tone, which implies substantial changes in conceptions of ratios, in particular, towards promoting the emergence of the idea of real number in theoretical music contexts.

KEYWORDS: mathematics/music, Renaissance concept of number, structural transformations

\section{INTRODUÇÃO}

Matemática e música já estavam relacionadas na Antiguidade. No conhecido experimento do monocórdio, atribui-se a Pitágoras o crédito de ter estabelecido uma correspondência entre intervalos musicais e razões matemáticas em uma corda. Tal experiência revela que determinados intervalos poderiam ser produzidos pela divisão da corda em razōes simples a:b de modo que $b$ representa a corda toda e $a$ uma parte da corda. Em particular, os intervalos musicais de oitava, quinta e quarta eram produzidos por razóes simples 1:2, 2:3 e 3:4, respectivamente. Tais consonâncias pitagóricas consistiam de intervalos, cujas razões subjacentes eram formadas somente por elementos da Tetraktys, ou seja, a série de números 1,2,3,4, cuja soma resulta em 10, que era visto como um número perfeito (SCRIBA, 1991,118).

A interrelação entre música grega e o desenvolvimento da matemática pura já havia sido abordada no início do século 20 por Paul Tannery (1915) e nos anos 70 por Arpad Szabo, quem também levantou questôes similares na tentativa de mostrar que a teoria pre-eudoxiana de proporção desenvolveu-se inicialmente como uma herança da teoria pitgórica de música (SZABO, 1978). Neste último, indicadores desta herança são encontrados vinculados a questôes tais como a restrição de Euclides na operação de composição de razões presente, embora não definida explicitamente, por exemplo, na proposição 23 do livro VI (HEATH, 1956, 247). Tal proposição afirma que paralelogramos equiangulares possuem proporcionalmente a razão composta da razão de seus lados (HEATH, 1956, 247). $\mathrm{Na}$ demontração, Euclides compunha duas razões BC:CG e DC:CE, adaptando-as a razões proporcionais K:L e L:M, respectivamente, tendo L em comum, antes de realizar a opera- 
ção. Assim, composição de razões usando o método clássico grego consistia de tomar razões do tipo $a: b$ com $b: c$ para produzir $a: c$, o que permitia a repetição deste processo com c:d e assim por diante, isto é, uma sequência de razões a serem compostas, de modo que o segundo termo de uma razão devia ser igual ao primeiro termo da razão subsequente. Assim, composição de razões no sentido clássico euclidiano significava a composição de razões a:b com c:d realizada encontrando-se uma grandeza $e$ de tal maneira que c:d fosse proporcional a b:e, resultando em uma razão composta a:e.

Tal procedimento possui fortes afinidades musicais, pois ele é estruturalmente semelhante a compor intervalos musicais contiguos no monocórdio. Utiliza-se aqui a expressão "compor" para expressar o processo em um contexto musical no qual dois intervalos musicais eram tomados de modo que a nota mais aguda do primeiro intervalo fosse igual a nota mais grave do segundo, de maneira a produzir um novo intervalo tal que sua nota mais grave fosse igual a nota mais grave do primeiro intervalo e sua nota mais aguda fosse a nota mais aguda do segundo.

Tal operação pode ser aplicada recursivamente. $\mathrm{Na}$ composição de intervalos com o monocórdio, se começa um dado intervalo a partir do ponto que se chegou no intervalo anterior, que corresponde matematicamente aos termos comuns entre razões subsequentes na operação de composição mencionada anteriormente, de modo à composição de razôes em matemática corresponder à composição de intervalos musicais em música.

No contexto do experimento de Pitágoras, ao se considerar que, por um lado, uma quarta que é produzida por 3:4, composta com uma quinta, que é produzida por $2: 3$, resulta musicalmente em uma oitava, que é produzida por 1:2; e por outro lado que, tal operação, que corresponde matematicamente a tomar 3:4 de uma corda seguido de tomar 2:3 do que resta, significa tomar (2:3)(3:4) da corda, isto é, (1:2) da cor$\mathrm{da}$; o experimento de Pitágoras parece nos informar mais do resultado geral de que razôes matemáticas subjazem a intervalos musicais. Ele nos diz mais especificamente que composição de razões subjazem a composição de intervalos musicais, e ainda que, provavelmente devido a este vínculo, a composição de razão no estilo euclidiano é manipulada desta forma. 
O experimento de Pitágoras representa o início de uma ciência voltada à matemática na Grécia. Ele mostra como uma ordem matemática é inerente ao espaço físico, portanto corroborando tal ordem como a origem e fundamento da harmonia. A descoberta de Pitágoras concernente ao monocórdio lança luzes em um vasto número de discussões sobre teoria musical tendo razões como base, tanto na Grécia como após o período helenístico. Esta característica conformou a concepção de música ocidental com uma compreensão matemático-especulativa até o Renascimento, quando uma concepção mais empírica começou a emergir.

No final do século XV e início do século XVI, em contextos matemáticos, mudanças na concepção de razão ocasionou o fortalecimento de teorias aritméticas de razão, contribuindo em um sentido mais amplo para a aritmetização de teorias de razão e ao mesmo tempo para o uso de geometria, invês de aritmética pitagórica como instrumento para resolver problemas estruturais em música teórica. Utiliza-se aqui o termo "aritmetização das teorias de razão", para descrever o processo em que, especialmente no final da Idade Média e início do período moderno, o conceito de razão matemática perde seu caráter geométrico, para assumir um caráter estruturalmente semelhante, mas semanticamente distinto. Por exemplo, razão matemática perde o significado de comparação entre duas grandezas de mesma natureza, aproximando-se semanticamente do conceito de número; composição de razóes torna-se multiplicação de razões e proporções entre razões matemáticas tornam-se gradativamente equações envolvendo números.

\section{ARITMETIZAÇÃo DE TEORIAS DE RAZÃo}

O complexo processo de aritmetização das teorias de razão no âmbito da matemática e da música iniciou-se na Grécia Antiga, desenvolvendo-se ao longo da Idade Média até o Renascimento. Tendo já recebido durante a Idade Média contribuições significativas das culturas latina, bizantina e árabe, este processo culminou no Renascimento com uma forte confluência destas tradições, o que levou a uma aceleração sem precedentes da aritmetização nas teorias de razão neste período.

Até o Renascimento, não havia no tratamento de razões uma estrutura bem definida. Em alguns casos, tal conceito 
era tratado aritmeticamente, em outros com características geométrico-musicais e outros ainda era manipulado como combinação destas tendências. A estas diferentes estruturais, que acompanharam os conceitos de razão e proporção desde a Antiguidade, correspondiam teorias, que fundamentaram os tratados de matemática e de música até o Renascimento.

No decorrer da história, muitos teóricos contribuíram para o processo de aritmetização de razões e de mudanças estruturais em suas teorias:

No século IV a.C., Aristoxeno de Tarento fez uso de intervalos musicais, e indiretamente razões, como grandezas unidimensionais contínuas, possibilitando com isto a divisão de intervalos.

No século IV d.C. Theon de Alexandria realizou interpolaçōes no livro VI de "Os Elementos" de Euclides, alterando consequentemente o sentido euclidiano original de composição de razōes.

No século XI, Psellus sugeriu uma divisão geométrica do tom. Partindo de contextos teórico-musicais, sua concepção implicava na interpretação de razão como um contínuo.

No século XIII, Campanus de Novara atribuiu um significado aritmético à definição 5 de sua tradução do árabe do livro V de "Os Elementos" de Euclides, ao inserir o novo termo "denominatio", embora não existente no texto original, propiciando transformaçôes significativas em teorias de razão.

No século XIV, Oresme introduziu o termo razões de razões, "proportio proportionium", com expoentes fracionários, proporcionando um método, que possibilitava a divisão de uma razão arbitrária em um número qualquer de partes.

No final do século XV e início do século XVI, Erasmus Horicius publicou pela primeira vez em contexto musical um tratado, que lidava com o conceito de razão como uma quantidade contínua.

No século XVI, as transformações mencionadas e o processo de aritmetização aceleravam-se até que finalmente no século XVII a teoria aritmética se tornasse predominante.

\section{CONTEXTO GERAL DO ESTUdO SOBRE RAZŌES}

A partir da segunda metade do século XX, desenvolveram-se diversas pesquisas acerca de teorias de razão e proporção na Idade Média, cujos resultados ampliaram significativamente a 
compreensão historiográfica acerca da matemática medieval, bem como do reflexo das tradições gregas mencionadas nesta última. Junto a Clagett (CLAGETT, 1953, 1964) com investigaçōes a respeito de matemática, assim como de suas relações com física na Idade Média, em cujo contexto razôes e proporções desempenham um papel fundamental; cabe-se ressaltar sobretudo trabalhos de Grant (1960), Murdoch $(1963,1968)$, Drake (1973), Molland $(1978,1983)$ e Sylla (1984). Os trabalhos de Murdoch influenciaram consideravelmente as pesquisas sobre teorias de razão e proporção neste período. Seus estudos fornecem não somente uma visão mais ampla acerca de teorias de razão e proporção, mas consistem, considerando trabalhos anteriores sobre o tema, em uma investigação detalhada de elementos específicos relacionados, por exemplo, à introdução do termo "denominatio" por Campanus, um indicador importante de modificações estruturais em tais teorias. Enquanto Molland tem como centro de sua pesquisa as reflexões de Bradwardine sobre razōes, Grant concentrou-se em Oresme e suas idéias de "Proportio proportionium". Já Sylla e Drake discutiram, sob diferentes perspectivas, a confusão de argumentos nas tradiçôes geométrica e aritmética das teorias de razão e proporção, o que evidencia a existência concomitante de estruturas híbridas em tais teorias já neste período pelo menos em matemática, teorias estas que competem e ganham prioridade dependendo do contexto de utilização. Enquanto Sylla investigou como tais tradições eram combinadas de maneira incomum dentro do contexto específico de composição e multiplicação de razões; Drake ocupou-se com os diversos modos de combinação dessas teorias no contexto das definições dos conceitos de razão e proporção utilizadas por teóricos medievais. Complementarmente a estes trabalhos, existem inúmeras traduções de fontes primárias, realizadas por Busard, Evans, Folkerts, Hoyrup, Lorch ou North.

A análise da terminologia de razóes e proporções presente em tratados de matemática e de teoria musical do século XVI, assim como de períodos um pouco anteriores e posteriores permitem identificar elementos de origem platônico-pitagórica bem como indicativos de transformações em tais elementos. Tal análise permite ainda realizar uma primeira avaliação acerca das transformações estruturais em teorias de razão e proporção, bem como detectar sinais de resistência a tais transformaçóes 
e da presença da tradição platônico-pitagórica neste processo. Como comentado, no que concerne ao papel da música grega no desenvolvimento da matemática pura, Arpad Szabo (1974) reuniu uma série de argumentos, que sustentam a tese, segundo a qual a teoria pré-eudoxiana de razão e proporção é uma herança da teoria musical pitagórica. Para essa finalidade, ele realizou uma análise minuciosa de termos técnicos gregos, na qual ambas teorias foram consideradas. Inúmeros autores trabalharam a respeito da influência platônico-pitagórica sobre a teoria musical em épocas posteriores. Por exemplo, Koehler (1990) analisou relaçōes platônico-pitagóricas em obras da Ars Nova e Ars Subtilior. Barbour (1933) mostrou que o temperamento pitagórico perseverou intensamente, embora novas formas de expressão musical já mostravam nitidamente, quão rígidos e restritos eram os modelos pitagóricos, cujos sistemas tonais eram baseados exclusivamente em grandezas comensuráveis. Barbera (1980) enfatizou a persistência da matemática antiga pitagórica no pensamento musical. Na presente análise referente às mudanças conceituais em teoria musical, cabe ressaltar como os termos técnicos analisados por Szabo foram transmitidos e em qual contexto tais termos e/ou vestígios deles aparecem no século XVI com o intuito de verificar, se eles, como elementos da tradição platônico-pitagórica, constituem um obstáculo para transformações em teorias de razão e proporção na teoria musical; e por outro lado, como a transmissão, por exemplo, de termos técnicos, tais como o "denominatio" mencionado anteriormente e outros que induzem a transformações em direção a significados aritméticos para razões e proporções, atuaram como catalizadores para as transformações mencionadas.

Outro aspecto também relacionado consiste na análise da utilização de estruturas de pensamento dedutivo e analógica no processo de plausibilidade e demonstração em música teórica, o que permite contribuir para uma compreensão mais profunda de até que ponto os conceitos de verdade e prova foram incorporados na música. Sob um ponto de vista mais geral, isto ainda nos permite mostrar com base nesta análise, até que ponto processos heurísticos e de axiomatização desempenharam um papel na tradição musical.

Desde a Antiguidade, há na música téorica tratados, que tentam seguir uma forma axiomática e consequentemen- 
te, provam proposições teórico-musical por meio de seqüências de inferências silogísticas no estilo de argumento dedutivo como, por exemplo, o tratado Sectio Canonis, atribuído a Euclides. Com base neste documento, Busch (1998) examinou o papel da matemática na teoria da música antiga. Boécio utiliza no De Institutione Musica (BOWER \& PALISCA, 1989) algumas das idéias já existentes no Sectio Canonis e transmite por meio deste, não somente a fonte, mas pelo menos em parte, a tradição do estilo dedutivo para a música teórica da Idade Média. Neste contexto, cabe-se mencionar o tratado Musica de Erasmus Horicius (PALISCA, 1994) do final do século XV e início do século XVI, que é construído em uma base axiomática geométrica no estilo euclidiano. Outras tentativas de axiomatização em contextos teórico-musicais se encontram em Zarlino (1571). Fend mostrou de modo convincente, que o tratado Dimostrationi Harmoniche de Zarlino pode ser interpretado como uma tentativa de axiomatizar a música teórica (FEND,1989). Ao mesmo tempo, existem ainda tratados de música teórica da Idade Média ao início do período moderno, que mostram uma forte presença do raciocínio analógico em sua estrutura argumentativa, uma vez que tais formas estão ancoradas aos fundamentos do pensamento pitagórico.

Concentra-se neste texto em uma importante contribuição do humanista Erasmus Horicius para as transformações mencionadas, a saber uma divisão igual numérica do intervalo de tom inteiro, que revela significativas transformações nas concepções de razão na direção de contribuir para a emergência da ideia de número real em contextos teório-musicais.

\section{O De musica speculativa de Erasmus Horicius}

O contexto mais amplo da passagem mencionada é aquele, em que problemas da música teórica ocidental vinham sendo tratados ao longo de sua história desde a Antiguidade até o Renascimento à luz de um modelo aritmético focado em uma atividade racional de especulação passando a ser vistos segundo um modelo matemático empírico com ênfase na qualidade do som em si, suas leis e efeitos nas pessoas. Neste contexto, Erasmus propôs uma divisão igual numérica do intervalo de tom inteiro, que pressupóe importantes transformaçóes nas concepções de razão, em particular, na direção de promover 
a emergência da ideia de número real em contextos teório-musicais.

Para isto, será considerada uma passagem presente no capítulo XVII do livro VI de Erasmus De musica, entitulada "Propositio decimaseptima Toni proportionem scilicet sesquioctavam in duas proportiones equales artificialiter et geometrice dividere ${ }^{l}$. Trata-se da divisão numérica igual e proporcional do intervalo de tom inteiro soando entre cordas com razão de comprimento 9 para 8, um problema que confundiu os teóricos musicais da Antigüidade até o Renascimento e que desempenhou um papel importante no processo histórico que levou à emergência do temperamento igual. Na passagem mencionada, Erasmus parece estar a ponto de resolver tal problema.

\section{DiviSÃO DO TOM}

O problema da divisão do tom surgiu da descoberta pitagórica da indivisibilidade numérica de uma razão superparticular ou epimórica, isto é, $\mathrm{n}: \mathrm{n}+1$, por meio de sua média geométrica, em particular, aplicável à divisão da razão 9:8. Dado $\mathrm{A}<\mathrm{x}<$ $\mathrm{B}$, onde $\mathrm{A}$ e $\mathrm{B}$ são inteiros e a razão $\mathrm{A}: \mathrm{B}$ é superparticular, $\mathrm{x}$ não pode ser ao mesmo tempo inteiro e cumprir a condição $A: x=x: B$, ou seja, ser a média geométrica de A e B. Matematicamente, a divisão igual do tom 8:9 fornece razōes envolvendo surdos ou razões incomensuráveis subjacentes a intervalos musicais. Estes procedimentos eram considerados impossíveis em música teórica, uma vez que tais intervalos poderiam ser determinados somente por razões de números inteiros.

Tentativas de dividir o tom foram realizadas, entretanto, na Antigüidade por Aristoxeno (século IV a.C.), quem concebeu a natureza teórica da música como essencialmente geométrica, compreendendo alturas, intervalos musicais e também distâncias como quantidades contínuas que deveriam seguir as regras da geometrica euclidiana e deveriam ser passíveis de ser divididas continuamente, o que inevitavelmente levanta questôes concernentes à natureza de razão matemáticas neste contexto. Aristoxeno rejeitou a posição dos pitagóricos, segundo a qual intervalos musicais poderiam ser expressos somente como razões matemáticas envolvendo números inteiros, afirmando ao invés disto, que o ouvido era a única orientação
1.Proposition

decimaseptima como

dividir a razão sequioctava

(isto é, 9:8) do tom

inteiro em duas partes

iguais, artificialmente e geometricamente. 
para o fenômeno musical (WINNINGTON-INGRAM, 1995, 592). Aristoxeno preferiu geometria à aritmética na resolução de problemas envolvendo relações entre alturas musicais e acreditava na possibilidade de dividir o tom em duas partes iguais, concebendo intervalos musicais e razóes como grandezas contínuas. Tal ideia desencadeou muitas reações expressas por exemplo no Sectio Canonis (BARBERA, 1991, 125) e mais tarde no De institutione musica (BOWER AND PALISCA, 1989, 88) de Boécio no início da Idade Média, que sustentou a uma forte tradição pitagórica em música teórica na Idade Média. Seguindo a tradição platônica-pitagórica, muitos teóricos musicais medievais mantiveram a impossibilidade de divisão igual do tom, o que levaria matematicamente a razóes incomensuráveis subjacentes a intervalos musicais. Tal posição começou a mudar no século XV e acabou por ser sistematicamente superada no início do Renascimento com teóricos tais como Nicolau de Cusa, Erasmus Horicius, Faber Stapulensis, Henricus Grammateus, Pedro Ciruelo, Juan Bermudo, dentre outros, que propuseram a divisão igual do tom por meio da geometria. Em seu Musica, Erasmus Horicius fez uso de um procedimento numérico abstrato para propor a solução do problema da divisão igual do tom, expressando como número a média geométrica entre os termos da razão 9:8 subjacente ao tom.

\section{O De musica speculativa de Erasmus Horicius}

O De musica de Erasmus Horicius surgiu em um momento em que redescobertas, traduções e publicações de fontes da Antiguidade, tais como as obras de Euclides, Arquimedes e Ptolomeu, aumentaram o interesse e desenvolvimento por teoria dos números. Certas lacunas no sistema numérico pitagórico eram significamente preocupantes, resultando em crises e mudanças conceituais na demarcação entre aritmética e geometria. Neste contexto, razões envolvendo grandezas incomensuráveis só poderiam ser discutidas no âmbito de quantidades contínuas e exigiriam a unificação de tais disciplinas, bem como a conquista da ideia de um número continuum na atividade matemática.

Particularmente com Erasmus, conceitos árabes e hindus foram muito influentes, na medida em que promoveram o 
desenvolvimento da matemática grega e trataram entidades como números negativos e irracionais, assim como permitiram, com a introdução dos numerais hindus por Fibonacci, cálculos de complexidade sem precedentes e o desenvolvimento de números extremamente grandes, sendo este último uma importante componente na divisão da razão do tom inteiro de Erasmus, como será visto em seguida.

No décimo sétimo capítulo do livro VI, Erasmus refere-se especificamente à divisão da razão 9:8, o que representa o intervalo musical de um tom inteiro. Nos quatro capítulos anteriores do livro VI, Erasmus demonstrou de forma incompleta a divisibilidade em partes iguais de outras razões superparticulares e proporcionais, tais como a oitava (2:1), a quarta (4:3), a quinta (3:2) e terça menor (6:5).

Nesta passagem, Erasmus propôs um procedimento numérico abstrato para encontrar a média geométrica entre os termos da razão 9:8 subjacente ao tom, expressando-a como um número. Ele não utilizou a construção geométrica da média proporcional entre dois segmentos da proposição 13 do Livro VI de Euclides, como fez, por exemplo, Jacques Lefevre d'Etaples em 1496, por meio de métodos euclidianos exclusivamente não numéricos realizáveis com régua e compasso. Ao invés disso, Erasmus tentou chegar a uma expressão para a razão subjacente às metades supostamente igualmente proporcionais do intervalo de tom inteiro fazendo uso de números muito grandes. Ele realizou tal procedimento usando primeiramente a proposição 15 do livro V de "Os Elementos", que afirma que a:b :: am:bm. Seguindo este método, a metade da razão 9:8 do tom poderia ser obtida pela média geométrica da sua expansão nos termos 34828517376:30958682112. Tal razão era derivada diretamente da razão 9:8, multiplicando seu numerador e seu denominador pelo fator 3869835264 , ou seja, ele aplicou a proposição 15 do livro $\mathrm{V}$ para a $=9$ , $\mathrm{b}=8$ e $\mathrm{m}=3869835264$. A proporcionalidade entre 9:8 e 34828517376:30958682112 permite um mapeamento entre qualquer termo intermediário da razão 9:8, incluindo a média e sua expansão em uma razão de números grandes, considerando que o último é muito mais subdivisível. Uma vez que não havia frações decimais neste período, a razão proporcional extendida foi utilizada com a finalidade de extrair a raiz quadrada com um elevado grau de precisão, no caso, associada 
com grandes números inteiros em vez de casas após o ponto decimal. Erasmus não se preocupou em realizar qualquer cálculo no texto e ele não expressou, anacronicamente falando, seu resultado como uma aproximação do número real exato.

Erasmus é o primeiro autor a propor um procedimento numérico abstrato para um dado problema, expressando o resultado como número, contrariamente a usar a imagem ou construção de uma linha geométrica. Uma vez que este era um problema originalmente aritmético, ele deveria ser resolvido "artificaliter", ou seja, numericamente. Erasmus afirma que "...em demonstrações musicais nós somos forçados a utilizar todos os tipos de razóes... uma vez que todos os tipos de consonâncias e dissonâncias são baseadas em razões racionais e por esta razão nós não podemos deconsiderar razôes de surdos..." (Erasmus Horicius, fo. 61v). Erasmus propôs aqui razões incomensuráveis ou números irracionais em contextos musicais. Do ponto de vista de música teórica, a fim de fazer uso da teoria de Eudoxo do livro V de "Os Elementos" de Euclides na qual teorias de razão de surdos é baseada e que lida com quantidades abstratas com natureza continua, ele estabeleceu uma relação entre quantidades contínuas e discretas. Erasmus percebeu que a busca por uma média geométrica para a razão subjacente ao tom inteiro poderia não resultar em um número racional e invês de mudar o domínio neste ponto de quantidades discretas de números para quantidades contínuas de linhas geométricas, ele propôs um contínuo de números, embora não explicitamente, criando um espaço de pontos discreto muito denso entre os termos originais da razão 9 e 8 e sua expansão.

\section{CONSIDERAÇŌES FINAIS}

É plausível que se Erasmus realmente pensou que poderia dividir a razão sesquioitava em termos de uma operação puramente numérica, ele deve ter concebido pelo menos um conceito rudimentar de número continuo. Tal afirmação é corroborada por uma passagem posterior no capítulo 17, onde ele parece se referir diretamente à ideia de tal continuum, mencionando Boécio como um prisioneiro da doutrina pitagórica de número inteiro discreto não acessando todas as razões de números (ERASMUS HORICIUS, fo. 67v). Logo antes desta passagem, 
Erasmus afirma que a metade exata do intervalo de tom inteiro seria fornecida pela extração da raiz quadrada do produto de seus termos 8 e 9, que é a raiz quadrada de 72 (ERASMUS HORICIUS, fo. 67v). Mas ele não ralaciona explicitamente este resultado com os cálculos por ele apresentados.

Teoricamente baseado em muitas proposições geométricas e, incomumente em música teórica, modelado pelo estilo euclidiano, De Musica lida com razão como uma quantidade contínua, anunciando talvez o que emergeria como um tratamento aritmético de razões em contextos teórico-musicais durante o século XVI, manipulando-as como números reais. Erasmus poderia ter facilmente resolvido a divisão igual do tom fazendo uso da proposição de "Os Elementos" de Euclides, que fornece a média geométrica como a altura de um triângulo retângulo. Entretanto, faltando-lhe o conceito de infinito, ele tentou utilizar um método numérico para aproximar tal média, embora seu procedimento não se mostre explicitamente como uma aproximação do valor do número real da média geométrica.

BiBLIOGRAFIA

BARBERA, A.. The Euclidean Division of the Canon. Lincoln: University of Nebraska Press, 1991

BOWER, Calvin M. and Palisca, Claude V. (ed.).. Fundamentals of Music. Anicius Manlius Severinus Boethius. New Haven \& London: Yale University Press, 1989

ERASMUS HORITIUS. De Musica. Regin. Lat. 1245. Biblioteca Apostolica Vaticana

PALISCA, Claude V.. "The Musica of Erasmus of Höritz". In: C. Palisca (ed.). Studies in the History of Italian Music and Music Theory. Oxford: Clarendon Press, 1994. p. 146-67.

SCRIBA, Christoph J.. Zum historischen Verhältnis von Mathematik und Musik. In: Braunschweigische Wissenschaftliche Gesellschaft Jahrbuch 1990. p. 115-152.

TANNERY, Paul. Du Rôle De La Musique Grecque Dans Le Développement De La Mathématique Pure. In: P. Tannery, Memoires Scientifiques. Paris: Privat, 1915, p. 68-87 
WINNINGTON-INGRAM, R. P.. Aristonexus. In: SADIE, Stanley (ed.). The new Grove dictionary of music and musicians. London: Macmillan, 1995, p. 592. 